\title{
Sentidos sobre o/a Psicóloga/o no CRAS na Literatura Científica
}

\author{
Laura Vilela e Souza* \\ Universidade de São Paulo - USP, Ribeirão Preto, SP, Brasil \\ ORCID: https://orcid.org/0000-0003-0732-8175 \\ Fabio Scorsolini-Comin** \\ Universidade de São Paulo - USP, Ribeirão Preto, SP, Brasil \\ ORCID: https://orcid.org/0000-0001-6281-3371
}

\begin{abstract}
RESUMO
A partir do construcionismo social, o objetivo deste estudo de revisão narrativa foi compreender a produção de sentidos sobre o/a psicólogo/a nos Centros de Referência de Assistência Social (CRAS) veiculados na literatura científica, bem como caracterizar essa produção. Em uma busca nas bases/bibliotecas SciELO, LILACS, PePSIC e Google Acadêmico entre os anos de 2009 e 2017, recuperou-se 43 estudos. A maioria foi publicada em periódicos como Psicologia e Sociedade e Psicologia: Ciência e Profissão por autores/as provenientes dos Estados de Minas Gerais e Rio Grande do Norte, tratando-se de estudos empíricos por meio de entrevistas com psicólogos/as acerca de sua atuação no CRAS, bem como de análise de intervenções. A literatura é uníssona ao sugerir uma prática profissional alinhada ao sólido engajamento social e político, promovendo intervenções que se contraponham a modelos clínicos tradicionais, com foco no indivíduo e na patologia, ampliando as possibilidades do/a psicólogo/a como agente de transformação social.
\end{abstract}

Palavras-chave: intervenção psicossocial, atuação do psicólogo, Psicologia Social, SUAS.

\section{Meanings about the Psychologist at Social Assistance Service in The}

\section{Scientific Literature}

\begin{abstract}
Based on social constructionism theory, the objective of this narrative review study was to understand the meanings of the psychologist who work at the Social Care Referral Centers (CRAS) published in the scientific literature, as well as to analyze this production. By a search in the data bases SciELO, LILACS, PePSIC and Google Academic between the years of 2009 and 2017, 43 studies were identified. Most of them have been published in journals such as Psicologia \& Sociedade and Psicologia: Ciencia e Profissão, by authors from the Minas Gerais and Rio Grande do Norte states. These empirical studies bring interviews with psychologists about their work in CRAS, as well as analysis of their interventions. Literature is unified by suggesting a professional practice aligned with solid social and political engagement, promoting interventions that are opposed to traditional clinical models, focusing
\end{abstract}


on the individual and the pathology, expanding the possibilities of the psychologist as an agent of social transformation.

Keywords: psychosocial intervention, performance of the psychologist, Social Psychology, SUAS.

\title{
Sentidos acerca del Psicólogo en el Servicio de Trabajo Social en la
}

\author{
Literatura Científica
}

\section{RESUMEN}

A partir del construccionismo social, el objetivo de este estudio de revisión narrativa fue comprender la producción de sentidos acerca del/la psicólogo/a en los Centros de Referencia de Asistencia Social (CRAS) vehiculados en la literatura científica, así como caracterizar esa producción. En una búsqueda en las bases/bibliotecas SciELO, LILACS, PePSIC y Google Académico entre los años 2009 y 2017, se recuperó 43 estudios. La mayoría fue publicada en periódicos como Psicología y Sociedad y Psicología: Ciencia y Profesión por autores provenientes de las provincias de Minas Gerais y Rio Grande do Norte, tratándose de estudios empíricos por medio de entrevistas con psicólogos/as acerca de su actuación en el CRAS así como de análisis de intervenciones. La literatura es unísona al sugerir una práctica profesional alineada al sólido compromiso social y político, promoviendo intervenciones que se contraponen a modelos clínicos tradicionales, con foco en el individuo y en la patología, ampliando las posibilidades del/la psicólogo/a como agente de transformación social.

Palabras clave: intervención psicosocial, actuación del psicólogo, Psicología Social, SUAS.

A entrada dos/as psicólogos/as no campo da assistência social brasileira não é recente, mas é com a implementação do Sistema Único de Assistência Social (SUAS), em 2005, que os/as profissionais de Psicologia penetram maciçamente nesse campo (Yamamoto \& Oliveira, 2010). Esse processo fez com que os/as psicólogos/as tivessem que pensar suas práticas para atender a uma política pública com propósitos de proteção social, em níveis básico e especializado, em situações de extrema vulnerabilidade social e/ou pobreza.

Os Centros de Referência de Assistência Social (CRAS) são as entidades estatais responsáveis pelos serviços do nível de proteção básica. A proteção social básica prevê o atendimento de famílias com risco de rompimento de vínculos ou de violação de direitos, promovendo ações preventivas como fortalecimento de vínculos, informação, orientação e articulação com a rede de proteção social. A entrada do/a psicólogo/a nas equipes do CRAS 
foi marcada pela dúvida de muitos/as profissionais sobre como colocar em prática os propósitos desse serviço. Buscando responder a essas dúvidas, em 2007 o Centro de Referência Técnica em Psicologia e Políticas Públicas (CREPOP) do CFP lançou uma publicação na qual mencionava as referências técnicas para atuação do/a psicóloga/o no CRAS (Conselho Federal de Psicologia, 2007). Esse material afirmava que o trabalho do/a psicólogo/a deveria ter como objetivo favorecer a autonomia, a cidadania, atuar sobre a dimensão subjetiva das pessoas, focalizar os aspectos saudáveis das famílias atendidas, identificar recursos pessoais e comunitários, promover trocas de saberes, ajudar as pessoas a intervirem em sua realidade, incentivar a participação nas instâncias de controle social, colaborar no rompimento com processos de exclusão, entre outras ações.

Esse documento do CFP, ainda que tivesse a intenção de esclarecer as/aos psicólogos/as sobre como poderia ser sua atuação, não foi suficiente, na opinião de psicólogos/as trabalhadores do SUAS, para responder às dúvidas dos/as profissionais sobre como essas referências e diretrizes poderiam ser cumpridas (Silva \& Corgozinho, 2011). E foi criticado por valorizar uma atuação individualizante (Yamamoto \& Oliveira, 2010).

Para além da crítica aos referenciais disponíveis, os/as psicólogos/as relatavam falta de formação na graduação em Psicologia para o trabalho com grupos, na comunidade e em situação de pobreza, tendo sua formação prioritariamente voltada para a atuação clínica e hospitalar (Macedo \& Dimenstein, 2012), falta de capacitação para esse trabalho (Teixeira, 2010), falta de ideias para novas formas de atuação (Ximenes, Paula, \& Barros, 2009), confusão de papéis com relação ao assistente social (Pereira, Coelho, \& Hirata, 2012), nenhum conhecimento anterior sobre SUAS e receio de entrar na casa das pessoas nas visitas domiciliares (Von Dentz \& Oliveira, 2013), falta de conhecimento teórico e metodológico para o trabalho nesse contexto e preferência pela atuação em clínica individual (Oliveira et al., 2014), e dificuldade para entender sua identidade profissional fora de uma atuação clínica tradicional (Leão, Oliveira, \& Carvalho, 2014).

Em 2016, o CFP lançou uma nota técnica com parâmetros para atuação dos/as profissionais da Psicologia no SUAS, buscando complementar as referências de 2007 (Conselho Federal de Psicologia, 2016). Esse documento reconhece a necessidade de conhecimentos para essa atuação que extrapolem aqueles oferecidos por grande parte dos cursos de graduação em Psicologia. No âmbito da proteção social básica, aponta-se para a necessidade de intervenções críticas, preventivas, de promoção de ações comunitárias, do conhecimento do território, da realização de grupos, da identificação de demandas coletivas, da não realização de atendimentos psicoterapêuticos e de ações planejadas. 
Para além das produções dos conselhos de Psicologia, as pesquisas na área realizadas na última década também buscaram responder aos desafios da atuação no CRAS, com estudos que a partir de diferentes perspectivas teóricas pudessem colaborar na oferta de formas de atuação nesse contexto, estudos que buscaram entender os determinantes desses desafios, estudos para ouvir o que os/as profissionais precisariam para enfrentá-los e análise de intervenções que melhor responderiam aos objetivos de um serviço de proteção social básica. A partir da metodologia de revisão narrativa pautada no construcionismo social, o objetivo deste estudo foi compreender a produção de sentidos sobre o/a psicólogo/a no CRAS veiculados na literatura científica, bem como caracterizar essa produção. De forma específica, interessa-nos entender quais perspectivas teóricas sustentam esses diferentes sentidos, quais ideais de Psicologia eles almejam e quais os efeitos para o posicionamento do/a psicólogo/a no CRAS.

\section{Método}

A delimitação dos propósitos de uma revisão de literatura responde aos parâmetros de definição da própria ciência e suas regras de produção de conhecimento. No discurso tradicional em ciência, entende-se o conhecimento como cumulativo e como fruto de aproximações da realidade dos fatos - daí serem comuns nessa forma de definição de revisão aquelas que sistematizam e integram o conhecimento produzido.

A perspectiva construcionista social não se apresenta como interessada em mapeamentos, achados, descobertas de fatos ou explicações de fenômenos. Não é uma perspectiva teórico-metodológica como tradicionalmente se entende teoria e método. É uma proposta metateórica que investiga os próprios processos de produção de conhecimento e seus efeitos na produção de verdades (McNamee \& Hosking, 2011). Dessa forma, a revisão de literatura é a oportunidade privilegiada para se compreender esses processos, reconhecendo os objetos delineados nas pesquisas e os métodos que os produzem como construções sociais, fruto de negociações de inteligibilidade dentro de comunidades científicas específicas. Portanto, neste artigo, tomamos revisão de literatura como um ato de reflexão crítica sobre os circunscritores de um determinado tema de pesquisa, sobre as possibilidades que são criadas quando um fenômeno passa a ser descrito de determinadas maneiras, sobre quais valores e ideais de mundo são reforçados nessas descrições e sobre as relações de poder que nelas se estabelecem. Assim, a revisão de literatura deixa de ser uma organização cumulativa de 
descobertas de um campo, para se tornar a oferta de uma possibilidade de ordenamento da produção de sentidos em uma determinada área.

Nesta revisão, entendemos que compreender os diferentes sentidos produzidos na literatura científica sobre como deve ser o trabalho no CRAS traz a possibilidade de reflexão crítica sobre o que está sendo construído como a/o psicóloga/o ideal para esse serviço, sobre as características que vão sendo descritas como desejadas para essa/e profissional, as habilidades, instrumentos e teorias defendidas para esse trabalho e sobre os discursos sociais que atravessam a defesa dessas preferências. É a oportunidade de avaliar o conhecimento produzido em um campo, entendendo quais Psicologias são reforçadas, quais interesses de pesquisa são priorizados e o que eles dizem de nossas escolhas em pesquisa.

Para essa revisão, incluímos todos os artigos produzidos sobre Psicologia e CRAS desde 2009, ano da primeira publicação sobre o tema, até dezembro de 2017, data da revisão aqui realizada. A busca por esses artigos foi realizada nas bases eletrônicas SciELO, LILACS e PePSIC com os unitermos "Psicologia" e "CRAS" nos campos de busca "título", "resumo", "assunto" ou "palavras-chave", com textos completos disponíveis. Escolhemos unitermos amplos para conseguir a totalidade de artigos que abarcassem essa temática. Para garantir que havíamos realizado o mapeamento de toda a produção em artigos na área incluímos a consulta ao Google Acadêmico, o que permitiu a inclusão de artigos de revistas com menor número de indexadores e que não estavam disponíveis nas grandes bases de buscas selecionadas. Foram excluídos desta revisão: livros, capítulos, teses, dissertações, monografias, resumos, anais de congressos, resenhas, cartas, editoriais e obituários e artigos repetidos.

O total de artigos selecionados foi de 46 e esse material foi organizado a partir das categorias construídas a posteriori e que sumarizam os sentidos sobre o/a psicólogo/a no CRAS delineados. Esses sentidos podiam estar claramente explicitados na defesa de como o/a profissional deveria ser ou agir em sua atuação, ou poderiam ser inferidos a partir da crítica a uma ação do profissional nesse contexto. As categorias descritivas dos artigos foram discutidas a partir da produção de distintos sentidos sobre o/a psicólogo/a no CRAS. Esses sentidos foram discutidos a partir dos efeitos que produzem para construção identitária do/a psicólogo/a no CRAS e a partir das normativas do SUAS para esse serviço. 


\section{Resultados}

\section{Caracterização do corpus analítico}

Em termos da caracterização da produção, os estudos foram publicados entre os anos de 2009 e 2017, com frequências que mostram certa uniformidade na distribuição ao longo do período de referência, como pode ser visto na Figura 1.

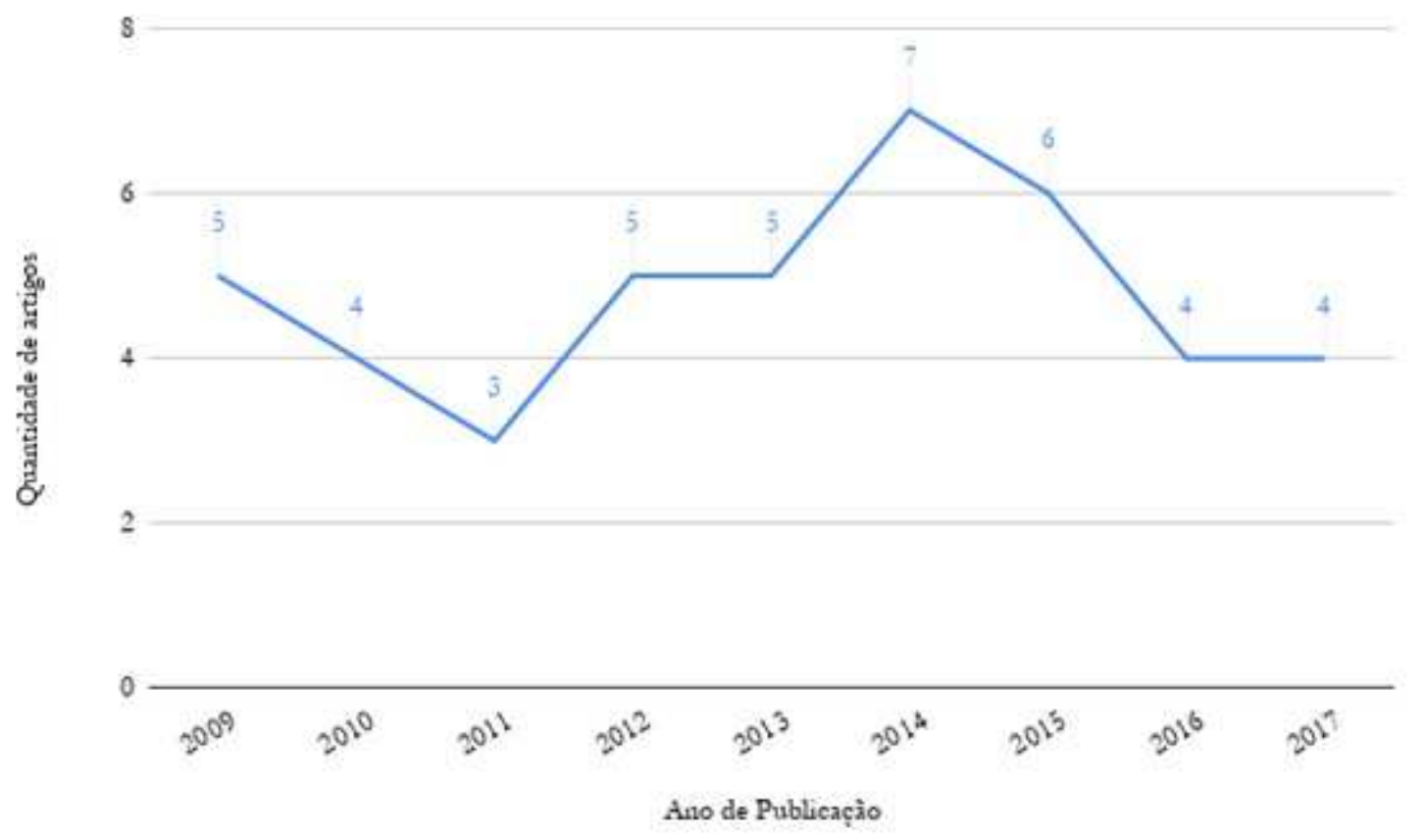

Figura 1. Quantidade de artigos publicados por ano de publicação

Os periódicos nos quais esses estudos foram divulgados estão apresentados na Tabela 1. 
Tabela 1

Quantidade de Artigos Publicados por Periódico

\begin{tabular}{ll}
\hline Periódico & N. de artigos \\
\hline Psicologia \& Sociedade & 9 \\
Psicologia: Ciência e Profissão & 7 \\
Nova Perspectiva Sistèmica & 3 \\
Fractal & 3 \\
Gerais: Revista Interinstitucional de Psicologia & 2 \\
Spagesp & 2 \\
Pesquisa e Práticas Psicossociais & 2 \\
Estudos e Pesquisas em Psicologia & 1 \\
EcoS & 1 \\
Diálogo & 1 \\
Barbarói & 1 \\
Avances em Psicologia Latinoamericana & 1 \\
Liberalit & 1 \\
Psicologia em Estudo & 1 \\
Psicologia em Foco & 2 \\
Psicologia: Teoria e Pesquisa & 1 \\
Revista Abordagem Gestáltica & 1 \\
Revista do Nufen & 1 \\
Revista Psicologia e Saúde & 1 \\
Textos e Contextos & 1 \\
Vínculo & \\
\hline & 1 \\
\hline
\end{tabular}

Os periódicos que concentram a maior parte das produções possuem políticas editoriais mais voltadas para a questão social, como a Psicologia e Sociedade ( $n=9)$, ou para a atuação da/o psicóloga/o, como Psicologia: Ciência e Profissão (n=7).

Os/as autores dos estudos são provenientes, em sua maioria, dos estados de Minas Gerais (n=17), Rio Grande do Norte $(n=17)$, Rio Grande do Sul $(n=14)$ e Piauí $(n=8)$. Em termos teóricos e metodológicos, a Tabela 2 sumariza as principais características dessas produções. 
Tabela 2

Tipos de Estudo, Métodos, Amostras e Enfoques Desenvolvidos no Corpus

\begin{tabular}{|c|c|}
\hline Perspectiva teórica & $\mathrm{N}$ \\
\hline $\begin{array}{l}\text { Articulação com literatura da área (legislação, normativas, referências } \\
\text { técnicas, etc.) }\end{array}$ & 16 \\
\hline Foucaultiana & 05 \\
\hline Teoria das Representações Sociais & 05 \\
\hline Teónicos da Psicologia Social Comunitánia & 05 \\
\hline Construcionismo social & 03 \\
\hline Esquizoanálise & 02 \\
\hline Psicanálise & 02 \\
\hline Abordagem Centrada na Pessoa & 02 \\
\hline Sistêmica & 02 \\
\hline Histórico-cultural (Vygotsky) & 03 \\
\hline Fenomenologia & 02 \\
\hline \multicolumn{2}{|l|}{ Tipo de estudo } \\
\hline Empirico & 25 \\
\hline Teórico & 12 \\
\hline Relato de Experiência & 08 \\
\hline Revisão bibliográfica & 01 \\
\hline \multicolumn{2}{|l|}{ Método } \\
\hline Entrevista & 22 \\
\hline Observação participante & 06 \\
\hline Questionário & 04 \\
\hline Levantamento bibliográfico/documental & 05 \\
\hline Inserção ecológica & 01 \\
\hline \multicolumn{2}{|l|}{ Procedimentos de análise dos dados } \\
\hline Análise de conteúdo temática & 13 \\
\hline Análise do discurso & 04 \\
\hline Redução fenomenológica & 02 \\
\hline Análise cartográfica & 01 \\
\hline Análise de trajetórias profissionais & 01 \\
\hline \multicolumn{2}{|l|}{ Público-alvo dos estudos empíricos } \\
\hline Profissionais & 25 \\
\hline Usuários & 06 \\
\hline \multicolumn{2}{|l|}{ Enfoque } \\
\hline Atuação da/o Psicóloga/o no CRAS & 15 \\
\hline Análise de intervenção psicológica no CRAS & 10 \\
\hline $\begin{array}{l}\text { Histórico da inserção e mapeamento das/os psicólogas/os na } \\
\text { Assistência Social }\end{array}$ & 06 \\
\hline Representações das/os psicólogas/os sobre usuárias/os & 04 \\
\hline Análise das relações cotidianas no CRAS & 02 \\
\hline Proposta teórico-metodológica para psicóloga/o no CRAS & 02 \\
\hline Análise dos modos de govemo no CRAS & 03 \\
\hline Representações/opinião das/os usuários sobre a/o psicólogo/a & 02 \\
\hline Caracterização da população atendida em um CRAS & 01 \\
\hline Revisão Bibliográfica & 01 \\
\hline
\end{tabular}

\section{Distintos posicionamentos epistemológicos}


A partir da Psicologia Social Comunitária (PSC), Silva e Corgozinho (2011) constroem o/a psicólogo/a no CRAS como aquele/a que tem compromisso social; possui uma leitura histórica de seu fazer; leva em conta saberes teóricos de origem latino-americana; não é elitista; tem compromisso com a transformação social; primeiro entra na comunidade, escuta a demanda e a partir daí e junto com a participação da população, organiza suas práticas; faz contato com lideranças comunitárias; conhece os sujeitos da comunidade; faz investigação etnográfica; participa de ações sociais, festas, eventos esportivos, de lazer e religiosos; faz parcerias com a comunidade; faz levantamento de recursos comunitários; avalia suas intervenções e tem a ética da solidariedade.

Também a partir da PSC, Ximenes, Paula e Barros (2009), defendem um/a psicólogo/a que desenvolve a consciência de sujeito histórico e ativo na criação de seu cotidiano; tem como foco a construção de significados das pessoas; olha para a singularidade e afetividade do/a usuário/a; toma o sofrimento em seus aspectos ético-políticos; desenvolve as potencialidades dos/as usuários/as; fortalece vínculos; tem como objeto de atuação os processos interacionais; não é paternalista e distante, nem satisfaz apenas necessidades imediatas; não promove dependência, nem submissão; não constrói hierarquia de saberes e posições; tem como espaço de atuação a convivência comunitária e as redes interativas que constroem pessoas e grupos; não psicopatologiza as pessoas; atua na compreensão subjetiva da realidade local e seus aspectos simbólicos, e não só nos aspectos econômicos e sociais; constrói conhecimento de maneira compartilhada, dialógica e colaborativa; atua predominantemente de forma grupal, em rede e coletivamente; se afeta pelos encontros; tem ações de transformação de contexto, de ampliação de espaços públicos, de promoção de socialização dos/as moradores/as e projetos de desenvolvimento comunitário; conhece o que já existe de recursos no território e sabe o que sentem e pensam os/as moradores/as; pensa a sustentabilidade de suas ações; constrói redes de apoio; ajuda os/as usuários/as a se constituírem criativamente; sabe que são necessárias diferentes políticas sociais para lidar com a situação de pobreza; critica os efeitos da lógica capitalista na construção da pobreza e desigualdade; prioriza demandas da comunidade e não da gestão; cria suas ações a partir do contexto e não de projetos externos e sabe que sua atuação não vai mudar sozinha as estruturas sociais, mas ainda assim o/a psicólogo/a deve seguir nessa direção.

Ainda na perspectiva da PSC, Costa e Cardoso (2010) apontam um/a psicólogo/a que tem uma escuta qualificada; é um facilitador de relacionamentos; favorece a convivência comunitária e a troca de experiências, e utiliza o diálogo para buscar soluções concretas e criativas. Já Senra e Guzzo (2012) mencionam um/a psicólogo/a que critica a Psicologia como 
instrumento de ideologia burguesa; não naturaliza os fenômenos psi; não desloca sua prática de uma ação política; analisa criticamente suas ações; compromete-se com a transformação social; rompe com o apoio histórico à classe social dominante; não reproduz o status quo; contextualiza a vivência das pessoas; constrói métodos e conceitos; olha para as condições concretas de vida da população; tem intervenções que englobam a complexidade do cenário social, assume sua função social e política.

Os artigos que tratam das representações sociais de psicólogos/as sobre os/as usuários/as, como por exemplo o estudo de Pereira e Guareschi (2017), defendem um/a psicólogo/a que não aceita acriticamente as normativas do CRAS/SUAS; atua preventivamente; não individualiza ou psicologiza os problemas sociais; problematiza um modelo normativo de família; problematiza intervenções de controle do Estado sobre as famílias; tem escuta atenta e diferenciada; resgata sua história como sujeito; compreende o/a usuário em sua coletividade; olha as demandas concretas dos/as usuários/as; efetiva direitos; entende a pluralidade de infâncias e adolescências; tem atuação crítica, reflexiva e investigativa; vê a pessoa em suas múltiplas relações na vida; busca entender por que os/as usuários/as não aderem às práticas ofertadas; e cria estratégias de adesão ao invés de criticar os/as usuários/as como passivos/as ou acomodados/as.

Os artigos que se fundamentaram nas teorias foucaultianas, tais como o estudo de Santos, Heckert e Carvalho (2017), apresentam os seguintes sentidos sobre o/a psicólogo/a no CRAS: como aquele/a que problematiza e entende a lógica de mercado por trás da noção do/a usuário/a do CRAS como improdutivo/a e necessitado/a versus o/a trabalhador/a que seria visto/a como produtivo/a; e problematiza qualquer instrumento de saber-poder sobre as famílias para seu controle, questionando em que medida as pessoas precisam posicionar-se como vulneráveis para receberem assistência. Partindo do pressuposto de que o CRAS pode funcionar como dispositivo de controle da população ao eleger a família como núcleo interventivo, o/a profissional deve se colocar a serviço de promover uma assistência e um cuidado que possam questionar essa lógica, não aprisionando esse público em performances de vulnerabilidade ou, por exemplo, promovendo exclusões como na naturalização do papel exclusivo das mulheres como mães e cuidadoras, o que pode ser visualizado na centralização da responsabilidade da gestão dos benefícios oferecidos pelo CRAS nas mulheres.

A partir da Psicologia Histórico-Cultural, Macedo, Pessoa e Alberto (2015) afirmam um/a psicólogo/a que tenha uma escuta atenta e diferenciada; compreenda o/a usuário/a como resultado de forças de relação e imersão em múltiplos contextos; entenda a pluralidade de infâncias e adolescências e atue de forma crítica, reflexiva e investigativa. Estudos que 
abordam a esquizoanálise, como o de Andrade e Romagnoli (2010), constroem os sentidos do/a psicólogo/a como aquele/a que não psicologiza os problemas sociais; cria e fomenta a novidade; tem uma atuação ousada, corre riscos; não patologiza, não classifica e não enquadra os/as usuários/as; combate a massificação e a hegemonia dos modelos sociais excludentes; critica a globalização; tem a arte da invenção e coletiviza suas demandas para promoção de enfrentamentos.

A partir da perspectiva construcionista social, Motta e Scarparo (2013) defendem um/a psicólogo/a que se "desconstrua e reinvente"; que saiba que "não existem respostas prontas" para o desafio de sua atuação; que tem uma prática inter e transdisciplinar e que atue a partir de princípios éticos. A partir da lógica sistêmica, Mendonça (2014) apresenta um/a psicólogo/a que não estuda o indivíduo de forma descontextualizada; desenvolve práticas transformadoras; é especialista "do contexto" da conversa, e não de seu "conteúdo", desconstruindo e se reinventando.

Os estudos que se utilizam da psicanálise, como o de Paula e Paiva (2015), apresentam os sentidos sobre o/a psicólogo/a como aquele/a que tem uma escuta diferenciada; reflete sobre os propósitos da instituição e seus atravessamentos na dimensão subjetiva do/a usuário/a; aponta ao/a usuário/a a dimensão de responsabilidade subjetiva quanto a seu posicionamento em laços sociais, considerando-se que todo sujeito tem que renunciar à satisfação de todas as exigências pulsionais na vida em comunidade e lidar com o mal-estar derivado dessas renúncias. No estudo de Ferrari (2009), o/a psicólogo/a foi contratado especialmente para supervisão de equipe e, desse lugar, e a partir do referencial psicanalítico, é entendido como aquele que circula os questionamentos na equipe; confronta verdades préconcebidas; conscientiza os/as profissionais da equipe sobre os seus sentimentos envolvidos na atuação no serviço; ajuda a equipe a lidar com a impotência e desesperança diante do risco social dos/as usuários/as; e ajuda a produzir uma escuta "mais clínica".

A partir da fenomenologia, Von Dentz e Oliveira (2013) defendem o exercício da clínica ampliada. Flor e Goto (2015), afirmam um/a psicólogo/a que tenha uma prática interdisciplinar; enfrente os atravessamentos institucionais dificuldades de funcionamento da rede; que se posicione como funcionário público; que atue de forma preventiva, ainda que conheça os desafios dessa atuação; e que entenda subjetividade e intersubjetividade como constitutivas da singularidade da pessoa.

Os artigos que dialogaram com diversos autores/as da literatura da área, como o de Oliveira et al. (2011) e Reis e Cabreira (2013), defendem um/a psicólogo/a que se recusa a realizar somente atividades burocráticas; planeja suas ações; não entende encaminhamento 
como sinônimo de ação em rede; considera a análise do território em suas ações; não faz laudos e pareceres fora de seu âmbito de atuação; tem sua identidade profissional garantida, sem que precise atuar de forma clínica; não está perdido/a por não poder utilizar psicoterapia no CRAS; atua junto às famílias residentes de áreas isoladas; cria intervenções destinadas a moradores/as do campo; tem conhecimentos sobre a Psicologia voltada para área rural; não fica reforçando a não efetividade de seu fazer, é persistente e tem perspectivas inovadoras.

A partir da abordagem centrada na pessoa (ACP), Mota e Goto (2009), abordam o/a psicólogo/a como aquele que reconhece a singularidade da pessoa; colabora na construção de um projeto terapêutico com o/a usuário/a; acolhe, orienta e contribui com a tomada de decisões. Já Souza, Barros Neta e Vieira (2012) falam de um/a psicólogo/a que não estuda o indivíduo descontextualizado; tem uma escuta politizada; não faz psicologia clínica tradicional; privilegia a demanda emocional imediata do/a usuário/a; identifica recursos pessoais; valoriza a experiência subjetiva; e entende o/a usuário/a como responsável por suas ações no mundo.

\section{Discussão}

Como pode ser observado nesta revisão, diferentes referenciais teóricos têm sido empregados na condução de intervenções no CRAS, aportes estes que trazem características específicas ao modo como psicólogos/as atuam nesse cenário. Para Silva e Carvalhaes (2016), as diferenças epistemológicas que orientam as proximidades e os distanciamentos entre as abordagens psicológicas sustentam práticas muitas vezes díspares em um mesmo cenário de atuação, a exemplo do CRAS. A noção de subjetividade, por exemplo, pode ser vista como resultado de processos de estruturação interna, remetendo a uma noção essencialmente individual, ou então ser compreendida a partir de operadores ambientais, contextuais, políticos e socioculturais, o que muda totalmente o modo de se atuar.

Todos os estudos dialogam com as normativas do SUAS para o trabalho no CRAS, mostrando alternativas para um trabalho do/a psicólogo/a que saia dos moldes da atuação clínica tradicional, leve em conta o contexto social e seja preventivo. Todavia, existe um maior ou menor distanciamento dessas tradições quando comparamos, por exemplo, uma intervenção como a de plantão psicológico da ACP ou de construção de parcerias com lideranças comunitárias para ações no território, como a proposta da PSC. O primeiro ainda se organiza em um setting privativo para essa atuação, com o enfoque individualizante (mesmo que com o olhar para o indivíduo em contexto), e tem a ideia de transformar o indivíduo para 
que ele/a transforme seu contexto. O segundo trabalha com um setting aberto, dinâmico, em constante reorganização, e tem no próprio contexto seu foco de ação. Também são distintas as formas de posicionamento do/a usuário/a nessas situações, ora o/a usuário/a ocupando o lugar de objeto de das intervenções, ora sendo colaborador da sua construção.

Com relação às hierarquias construídas no relacionamento psicólogo/a e usuário/a, os estudos da psicanálise - que apresentam um/a profissional com um lugar de especialista sobre o que o outro (no caso usuário/a ou equipe) deve saber, como é o caso da/o psicólogo/a que ajuda os/as demais profissionais a elucidarem seus sentimentos-, ou no caso do estudo que aborda o plantão psicológico Mota e Goto (2009) - no qual o/a psicólogo/a é posicionado como aquele que orienta o/a usuário/a - diferem daqueles da PSC, por exemplo, que posicionam o/a usuário/a como agente ativo na transformação social almejada. Na perspectiva construcionista social, o/a profissional se posiciona como especialista da conversa, ou seja, do "como" essa conversa vai acontecer, mas não decide o seu conteúdo, posicionando o/a usuário/a como aquele que vai decidir o que é importante ser falado.

Os diferentes sentidos sobre a atuação psi no CRAS tem como efeito a proposição de intervenções mais ou menos individualistas ou coletivistas. Há a possibilidade de a intervenção ter como foco o indivíduo, a família, os grupos, ou a comunidade como um todo. Esses sentidos constroem diferentes definições de "eu". A noção autocontida de um "eu" estruturado da psicanálise justifica que o/a psicólogo/a busque responsabilizar o/a usuário/a com relação ao seu papel no enfrentamento de suas problemáticas, o que é distinto, e com implicações éticas outras, do entendimento da PSC do indivíduo como uma realidade social, histórico e cultural, ou da Psicologia Histórico-Cultural que entende a pessoa como resultado de forças de relação e imersão em múltiplos contextos, ou, ainda, da teoria das representações sociais que toma a pessoa em suas relações. Assim, podem ser tomados como objetos da atuação psicológica a experiência subjetiva da pessoa, como nos estudos que mencionaram a ACP, ou os significados construídos pelos/as usuários/as e os processos interacionais, como na PSC ou o próprio relacionamento profissional-usuário/a como no construcionismo.

Há também a diferença entre a menção do uso de estratégias psicológicas já consolidadas na profissão, como a de supervisão de equipe e plantão psicológico, e a defesa de que o/a psicólogo/a crie seus próprios conceitos e métodos de trabalho, como defendido pelos estudos da PSC, esquizoanálise e construcionismo social, por exemplo. O que justificaria esse fomento da novidade seria a possibilidade de responder às demandas que se colocam nas situações cotidianas, em sua complexidade e dinamismo. O enfoque nas potencialidades dos/as usuários/as e nos recursos do território é defendido nos estudos da 
PSC, foucaultianos, esquizoanalíticos, e outros, aspecto que conversa com as diretrizes para atuação na proteção social básica disponíveis na busca por uma atuação de caráter preventivo.

A forma de resposta às críticas a um fazer próprio de uma Psicologia tradicional são variadas. Vão desde a proposta de uma clínica ampliada, como os estudos de fenomenologia apregoam, passam pela proposta de uso das teorias não hegemônicas na Psicologia, como os estudos da PSC mencionam, até a invenção de conceitos e métodos, como falam os estudos da esquizoanálise e construcionistas sociais. Há a defesa na maior parte dos estudos de um posicionamento político do/a psicólogo/a em sua atuação, inclusive com o entendimento de que seu fazer é político por natureza. O caráter político dessa atuação evoca-se na crítica ao elitismo, ao modo capitalista de organização social, à lógica do mercado, à globalização, à culpabilização do/a usuário/a pela sua situação de pobreza e pela não adesão ao serviço; ao controle do governo sobre as famílias e até às próprias normativas do SUAS.

A noção de compromisso social e transformação social aparecem nos estudos da PSC e naqueles que dialogam de forma mais ampla com a literatura da área, como a expressão dessa politização do/a psicólogo/a. Excede as possibilidades desta revisão abarcar a polissemia desses conceitos, como bem faz Sawaia (2014) com relação à noção de transformação social, ou Yamamoto (2007) com a noção de compromisso social. Mas cabe destacar que esses conceitos marcam a própria história da Psicologia e os debates sobre os propósitos da profissão. Em comum, esses conceitos marcam a necessidade do/a psicólogo/a se posicionar frente à situação de desigualdade social brasileira, produzindo ações que, a depender da teoria que sustenta a noção de transformação social evocada, vão desde estar consciente do seu compromisso ou denunciar essa situação até promover de forma revolucionária a sua mudança.

Com relação a como o/a psicólogo/a pode responder aos desafios da atuação no CRAS, os estudos apontam estratégias que exigem um menor ou maior voluntarismo do/a psicólogo/a, como aqueles que propõem que ele/a seja motivado e persistente (Leão, Oliveira, \& Carvalho, 2014), ousado e capaz de correr riscos (Andrade \& Romagnoli, 2010), ou que seja capaz de se reinventar (Mendonça, 2014), até aqueles que entendem ser necessário o apoio de coletivos profissionais para o enfrentamento desses desafios (Romagnoli, 2016).

Cabe a problematização da figura desse/a profissional como onipotente, de modo que a literatura enfatiza o seu expressivo papel na promoção de revisões que marcam a própria atuação em Psicologia. Desse modo, é preciso responder a essas expectativas e considerar que toda mudança ou ruptura com paradigmas construídos por décadas requer tempo, 
disponibilidade e um investimento em discussões acerca da formação profissional, da organização da categoria e dos próprios sistemas do SUAS e do CRAS.

Na política pública de assistência social, segundo orienta o Conselho Federal de Psicologia (2016), as intervenções devem considerar uma avaliação das forças políticas que atravessam sua prática e as consequências de sua forma de atuação e dos serviços em que está inserido o/a profissional. Fundamental nesse processo decorrente dessa orientação é que esses/as profissionais se organizem coletivamente e politicamente, ocupando os espaços de articulação política do SUAS e no controle social. O Conselho sugere a participação em conselhos profissionais e sindicatos, bem como em fóruns de trabalhadores, o que significa uma nova perspectiva de atuação bastante distanciada das práticas veiculadas até mesmo como da ordem da chamada "clínica social". Promover a articulação das famílias usuárias, das organizações e movimentos comunitários e populares no território tem sido um desafio perene, conforme retratado na literatura da área.

Romagnoli (2012) destaca os aspectos da macropolítica que atravessam as atuações dessas/es profissionais no CRAS, como a burocracia e as dificuldades de gestão. Além dessas questões, a autora destaca um enrijecimento das práticas profissionais que acabam sustentando a/o psicóloga/o como alguém preso em modelos hegemônicos que são, em sua maioria, patologizantes e priorizam uma determinada descrição de ser humano, com pouco espaço para a consideração de aspectos sociais, culturais, políticos e relacionais. Esses elementos promovem uma atuação que, por vezes, pode estar cindida no sentido de que não ocorre um diálogo entre a política e o que ocorre na prática. Ao atuar sem essa consideração do contexto, os/as profissionais tendem a reproduzir modelos hegemônicos e que pouco dizem desse lugar de transformação social assumido - ou pelo menos almejado - pelo CRAS.

\section{Considerações Finais}

Embora a literatura recuperada seja uníssona em destacar o compromisso do/a psicólogo/a com a transformação de práticas profissionais no âmbito do SUAS, é importante considerar que os saberes psicológicos por vezes são apresentados como um locus de poder, de modo que abdicar desse lugar é colocar em discussão a própria construção do que é a atuação em Psicologia na contemporaneidade, e até mesmo a necessidade desse saber-fazer como ele se apresenta até então. A Psicologia tem respondido suficientemente às necessidades observadas no SUAS? Esses/as profissionais têm se comprometido com uma mudança de paradigma em termos de intervenções e mesmo de olhares lançados aos fenômenos humanos? 
O cenário do CRAS coloca em xeque essa atuação ao demandar um novo perfil, perfil este que ainda encontra pouco amparo nos currículos tradicionais em nosso país. Se considerarmos o caráter ainda jovem dessa profissão no Brasil, podemos advogar que o espaço posto na contemporaneidade é o de revisão de práticas.

É mister que o movimento de ruptura e de transformação possa ser acompanhado e também fortalecido pelos/as profissionais que têm atuado no SUAS, de modo que a prática possa direcionar revisões teóricas e epistemológicas importantes que dizem respeito à própria identidade dessa categoria. É preciso amadurecer as especificidades do trabalho do/a psicólogo/a nesse cenário, mas também promover a recusa a argumentos tradicionalmente empregados e que sustentam uma determinada posição de saber-poder, como a individualização e a psicologização no tratamento dos sujeitos e na própria abordagem da pobreza e das vulnerabilidades.

Os limites da revisão realizada foram dados pelo próprio recorte escolhido (qual seja, a análise dos sentidos sobre o/a psicólogo/a no CRAS produzidos na literatura), não permitindo realizar uma discussão aprofundada das teorias que sustentam esses sentidos em termos das diferentes psicologias construídas por elas e de suas aproximações e distanciamentos epistemológicos. A revisão mostra que a literatura da área tem sugerido significativos direcionadores para a atuação do/a psicólogo/a no CRAS. Estudos futuros poderão, por meio de desenhos metodológicos participativos e colaborativos, fomentar a produção de conhecimentos que coloquem em prática esses modos de fazer.

\section{Referências}

Andrade, L. F., \& Romagnoli, R. C. (2010). O Psicólogo no CRAS: Uma cartografia dos territórios subjetivos. Psicologia: Ciência e Profissão, 30(3), 604-619. doi:10.1590/S1414-98932010000300012

Conselho Federal de Psicologia (2007). Referências técnicas para atuação do(a) psicólogo(a) no CRAS/SUAS. Brasília, DF: Autor.

Conselho Federal de Psicologia (2016). Nota técnica com parâmetros para atuação dos(as) profissionais da Psicologia no âmbito do Sistema Único de Assistência Social (SUAS). Brasília, DF: Autor.

Costa, A. F. S., \& Cardoso, C. L. (2010). Inserção do psicólogo em Centros de Referência de Assistência Social - CRAS. Gerais: Revista Interinstitucional de Psicologia, 3(2), 223-229.

Recuperado

de 
http://pepsic.bvsalud.org/scielo.php?script=sci_arttext\&pid=S1983-

$82202010000200011 \& \operatorname{lng}=\mathrm{pt} \& \operatorname{tlng}=\mathrm{pt}$

Ferrari, R. (2009). Escutando famílias na rede pública: Uma experiência de supervisão institucional com a equipe do PAIF - Programa de Atenção Integral à Família dos CRAS, Vinhedo/SP. Revista da SPAGESP, 10(2), 27-32. Recuperado de http://pepsic.bvsalud.org/scielo.php?script=sci_abstract\&pid=S1677-

29702009000200005

Flor, T. C., \& Goto, T. A. (2015). Atuação do psicólogo no CRAS: Uma análise fenomenológico-empírica. Revista da Abordagem Gestáltica, 21(1), 22-34. Recuperado de http://pepsic.bvsalud.org/scielo.php?script=sci_arttext\&pid=S1809$68672015000100004 \& \operatorname{lng}=\mathrm{pt} \& \operatorname{tlng}=\mathrm{pt}$

Leão, S. M., Oliveira, I. M. F. F., \& Carvalho, D. B. (2014). O Psicólogo no Campo do BemEstar Social: Atuação junto às famílias e indivíduos em situação de vulnerabilidade e risco social no Centro de Referência de Assistência Social (CRAS). Estudos e Pesquisas em Psicologia, 14(1), 264-289. Recuperado de http://pepsic.bvsalud.org/scielo.php?script=sci_arttext\&pid=S180842812014000100015

Macedo, J. P., \& Dimenstein, M. (2012). O trabalho dos psicólogos nas políticas sociais no Brasil. Avances en Psicología Latinoamericana, 30(1), 182-192. Recuperado de http://www.scielo.org.co/pdf/apl/v30n1/v30n1a15.pdf

Macedo, O. J., Pessoa, M. C. B, \& Alberto, M. F. P. (2015). Atuação dos Profissionais de Psicologia Junto à Infância e à Adolescência nas Políticas Públicas de Assistência Social. Psicologia: Ciência e Profissão, 35(3), 916-931. doi:10.1590/19823703000922014

McNamee, S., \& Hosking, D. M. (2011). Research and social change: A relational constructionist approach. Oxford: Routledge.

Mendonça, R. T. (2014). A metodologia de atendimento sistêmico de famílias e redes sociais no Centro de Referência de Assistência Social: Uma proposta teórica e prática. Nova Perspectiva Sistêmica, 23(50), 74-88. Recuperado de http://www.revistanps.com.br/nps/article/view/92/82

Mota, S. T., \& Goto, T. A. (2009). Plantão psicológico no CRAS em Poços de Caldas. Fractal: Revista de Psicologia, 21(3), 521-529. doi:10.1590/S198402922009000300007 
Motta, R. F., \& Scarparo, H. B. K. (2013). A psicologia na assistência social: Transitar, travessia. Psicologia \& Sociedade, 25(1), 230-239. doi:10.1590/S010271822013000100025

Oliveira, I. F., Dantas, C. M. B., Solon, A. F. A. C., \& Amorim, K. M. O. (2011). A prática psicológica na proteção social básica do SUAS. Psicologia \& Sociedade, 23(spe), 140-149. doi:10.1590/S0102-71822011000400017

Oliveira, I. F., Oliveira, N. L. A, Nascimento, M. N. C, Araújo, R. L., Coelho-Lima, F., \& Amorim, K. M. O. (2014). Atuação dos psicólogos nos CRAS do interior do RN. Psicologia \& Sociedade, 26(spe2), 103-112. doi:10.1590/S0102-71822014000600011

Paula, F. O. Q., \& Paiva, J. (2015). Possibilidades de atuação do psicanalista no Centro de Referência de Assistência Social. Vínculo - Revista do NESME, 12(1), 41-50. Recuperado de http://pepsic.bvsalud.org/pdf/vinculo/v12n1/v12n1a07.pdf

Pereira, V. T., \& Guareschi, P. A. (2017). A psicologia no CRAS: Um estudo de representações sociais. Psicologia \& Sociedade, 29, e119584. doi:10.1590/18070310/2017v29119584

Pereira, C. P. G., Coelho, R. P. S., \& Hirata, R. M. (2012). Três saberes a serviço das famílias: Uma discussão sobre a supervisão das equipes dos centros de referência de assistência social. Nova Perspectiva Sistêmica, (43), 73-83. Recuperado de Www.revistanps.com.br/index.php/nps/article/download/264/256

Reis, R. G., \& Cabreira, L. (2013). As políticas públicas e o campo: E o Psicólogo com isso?

Psicologia: Ciência e Profissão, 33(spe), 54-65. Recuperado de http://www.scielo.br/scielo.php?script=sci_arttext\&pid=S141498932013000500007\&lng=en\&tlng=pt

Romagnoli, R. C. (2012). O SUAS e a formação em psicologia: Territórios em análise. Ecos, 2(1), 120-132. Recuperado de http://www.periodicoshumanas.uff.br/index.php/ecos/article/viewFile/683/662

Romagnoli, R. C. (2016). Relações macropolíticas e micropolíticas no cotidiano do cras. Psicologia \& Sociedade, 28(1), 151-161. doi:10.1590/1807-03102015v28n1p151

Santos, K. L., Heckert, A. L. C., \& Carvalho, S. V. (2017). Família e mulher como instrumentos de governo na assistência social. Psicologia \& Sociedade, 29, e158080. doi:10.1590/1807-0310/2017v29158080.

Sawaia, B. B. (2014). Transformação social: Um objeto pertinente à psicologia social? Psicologia \& Sociedade, 26(spe2), 4-17. doi:10.1590/S0102-71822014000600002 
Senra, C. M. G., \& Guzzo, R. S. L. (2012). Assistência social e psicologia: Sobre as tensões e conflitos do psicólogo no cotidiano do serviço público. Psicologia \& Sociedade, 24(2), 293-299. https://dx.doi.org/10.1590/S0102-71822012000200006

Silva, R. B., \& Carvalhaes, F. F. (2016). Psicologia e políticas públicas: Impasses e reinvenções. Psicologia \& Sociedade, 28(2), 247-256. doi:10.1590/1807$03102016 \mathrm{v} 28 \mathrm{n} 2 \mathrm{p} 247$

Silva, J. V., \& Corgozinho, J. P. (2011). Atuação do psicólogo, SUAS/CRAS e Psicologia Social Comunitária: Possíveis articulações. Psicologia \& Sociedade, 23(spe), 12-21. doi:10.1590/S0102-71822011000400003

Souza, E. L. C., Barros Neta, F. T., \& Vieira, E. M. (2012). Interface do plantão psicológico e as políticas de assistência social. Revista do NUFEN, 4(2), 71-82. Recuperado de http://pepsic.bvsalud.org/scielo.php?script=sci_arttext\&pid=S2175$25912012000200008 \& \operatorname{lng}=p t \& t \operatorname{lng}=p t$

Teixeira, S. M. (2010). Trabalho interdisciplinar nos CRAS: Um novo enfoque e trato à pobreza? Textos \& Contextos, 9(2), 286-297. Recuperado de http://revistaseletronicas.pucrs.br/ojs/index.php/fass/article/viewFile/7032/5781

Von Dentz, K. K. M., \& Oliveira, E. L. C. (2013). O psicólogo no CRAS: Uma nova experiência. Psicologia em Foco, 5(5), 82-100. Retrived from: http://revistas.fw.uri.br/index.php/psicologiaemfoco/article/view/1103/1580

Ximenes, V. M., Paula, L. R. C., \& Barros, J. P. P. (2009). Psicologia comunitária e política de assistência social: Diálogos sobre atuações em comunidades. Psicologia: Ciência e Profissão, 29(4), 686-699. doi:10.1590/S1414-98932009000400004

Yamamoto, O. H. (2007). Políticas sociais, "terceiro setor" e "compromisso social": Perspectivas e limites do trabalho do psicólogo. Psicologia \& Sociedade, 19(1), 30-37. doi:10.1590/S0102-71822007000100005

Yamamoto, O. H., \& Oliveira, I. F. (2010). Política Social e Psicologia: Uma trajetória de 25 anos. Psicologia: Teoria e Pesquisa, 26(spe), 9-24. doi:10.1590/S010237722010000500002

\section{Endereço para correspondência}

\section{Laura Vilela e Souza}

Universidade de São Paulo

Departamento de Psicologia - Faculdade de Filosofia, Ciências e Letras de Ribeirão Preto 
Av. dos Bandeirantes, 3900, Campus Universitário, Monte Alegre, Ribeirão Preto - SP, Brasil. CEP 14040-902

Endereço eletrônico: laura@ffclrp.usp.br

\section{Fabio Scorsolini-Comin}

Universidade de São Paulo

Departamento de Enfermagem Psiquiátrica e Ciências Humanas da Escola de Enfermagem de Ribeirão Preto Av. dos Bandeirantes, 3900, Campus Universitário, Monte Alegre, Ribeirão Preto - SP, Brasil. CEP 14040-902

Endereço eletrônico: fabio.scorsolini@usp.br

Recebido em: 27/02/2019

Reformulado em: 20/12/2019

Aceito em: 13/01/2020

\section{Notas}

* Psicóloga, Mestre e Doutora em Psicologia pela Universidade de São Paulo e Docente da Faculdade de Filosofia, Ciências e Letras de Ribeirão Preto da Universidade de São Paulo.

** Psicólogo, Mestre e Doutor em Psicologia pela Universidade de São Paulo e Docente da Escola de Enfermagem de Ribeirão Preto da Universidade de São Paulo.

Financiamento: Auxílio Regular Fapesp para primeira autora: Processo n. 2015/082224-0

Este artigo de revista Estudos e Pesquisas em Psicologia é licenciado sob uma Licença Creative Commons Atribuição-Não Comercial 3.0 Não Adaptada. 